\title{
The effect of fresh stem juice extract of Costus afer on the cytohistomorphology of the kidney in aspirin-treated Wistar rats
}

\author{
Idorenyin $\mathrm{U} \mathrm{Umoh}^{1 *}$, AN Aquaisua ${ }^{1}, \mathrm{NM} \mathrm{Udo}^{2}$ \\ ${ }^{1}$ Department of Anatomy, University of Uyo, Uyo, Akwa Ibom State, Nigeria, ${ }^{2}$ Department of Pharmacology and Toxicology, University of Uyo, Uyo, \\ Akwa Ibom State, Nigeria
}

\section{ARTICLE INFO}

Article history:

Received on: May 23, 2018

Accepted on: September 16, 2018

Available online: January 15, 2019

Key words:

Costus afer,

Aspirin,

Kidney,

Histology,

Nephrotoxicity

\begin{abstract}
The effect of fresh stem juice extract of Costus afer on cytohistomorphology of the kidney in aspirin-treated Wistar rats was evaluated. 25 rats weighing $150-180 \mathrm{~g}$ used for the study were divided into five groups with five rats in each group. Group 1 served as control while Group 2 was administered $150 \mathrm{mg} / \mathrm{kg}$ bw of aspirin daily for 28 days, Group 3 received $67.08 \mathrm{mg} / \mathrm{kg}$ bw of the extract of $C$. afer for 28 days, Group 4 was administered $150 \mathrm{mg} / \mathrm{kg}$ of aspirin and $67.08 \mathrm{mg} / \mathrm{kg}$ of the extract for 28 days while Group 5 was administered $150 \mathrm{mg} / \mathrm{kg}$ of aspirin for 14 days and then $67.08 \mathrm{mg} / \mathrm{kg}$ of the extract for another 14 days. Kidneys were harvested for histological studies. The results revealed that Group 1 showed normal histological features, Group 2 showed tubular necrosis, collapsed urinary space, and distorted glomerulus, Group 3 presented near normal features, Group 4 showed enlarged urinary space, inflamed tubular cells and reduced podocytes in the glomerulus compared to Group 2, and Group 5 revealed regeneration of cellular features already destroyed by aspirin. In conclusion, fresh stem juice extract of $C$. afer has ameliorative and protective potentials on nephrotoxicity of aspirin in albino Wistar rats.
\end{abstract}

\section{INTRODUCTION}

Recent studies show that in Asia and Africa, $80 \%$ of the population rely on traditional or alternative medicine for their primary health care needs [1]. Traditional medicine includes formalized aspects of folk medicine [2], and it is believed to be more readily accessible, cheap, and highly effective [1]. However, the World Health Organization also notes that inappropriate use of traditional medicine or practices can have negative or dangerous effects; thus, further researches are needed to ascertain the efficacy and safety of several medicinal plants used by traditional medicine system [1]. There are presently numerous plants under investigation for discovery of their medicinal potentials and Costus afer has attracted varied attention due to its wide consumption in rural communities.

C. afer is a traditional medicinal plant widely known as "ginger lily or bush cane" in English, "Okpete" or "Okpoto" in Igboland, "Kakizawa" in Hausa, "tete-egun" in Yoruba, and "Mbritem" in Efik all in Nigeria. Anglophone Cameroon calls it "Monkey sugar cane," Costus or gingembre spirale in French, and Fiaipqueté in Portuguese [3,4]. The plant is a perennial and rhizomatous herb of the genus Costus [5].

\footnotetext{
*Corresponding Author:

Dr. Idorenyin U Umoh, Department of Anatomy, University of Uyo, Uyo,

Akwa Ibom State, Nigeria. Tel.: +234(0)8036743886.

E-mail: umohidorenyin_dr@yahoo.com
}

C. afer is commonly found in the forest zones of most places, including Senegal, Nigeria, South Africa, Guinea, Ghana, and Cameroun and most regions in tropical Africa, particularly in higher rainfall areas $[4,6]$. C. afer is widely used as a medicinal plant in tropical Africa and several uses have been confirmed by pharmacological studies, and it has some value as an ornamental plant [7]. The plant is used as a remedy for cough, inflammation, laxative, purgative, diuretic, and treatment of several other diseases [8]. Furthermore, ethanol and aqueous extracts from both stems and leaves of C. afer have been reported to have nephroprotective activities [9].

Phytochemical analysis revealed various chemical constituents in aqueous and ethanol extracts from both stems and leaves of C. afer. The results indicated the presence of alkaloids and tannins in aqueous extract [10]. Alkaloids are known to have an antimicrobial, antifungal, and anti-inflammatory effect, and it also acts as an anti-hypertensive agent [11]. The folkloric use of C. afer in the treatment of sore throat, diarrhea, hemorrhage, and wound healing might be due to the presence of tannins [12]. Cardiac glycosides and anthraquinones tested positive in methanol and aqueous extracts [10]. Cardiac glycosides have been reported to be effective in the treatment of congestive heart failure and regulation of heartbeat [13]. Anthraquinones can induce a laxative effect [14] and hence, the use of $C$. afer as a laxative and nervous system depressant [15]. Flavonoids and phenols were abundant in aqueous extract. These are potent water-soluble antioxidants which prevent oxidative cell damage; it also has antiseptics, anticancer, antiinflammatory effects, and mild anti-hypertensive properties $[12,16]$. 
In the present study, the effect of the fresh stem juice extract of $C$. afer on the cytohistomorphology of the kidney in aspirin-treated Wistar rats was investigated.

\section{MATERIALS AND METHODS}

\subsection{Materials}

Aspirin was obtained from Sigma-Aldrich, C. afer stems were obtained from the city of Uyo, identified and authenticated by a taxonomist in the Department of Botany and Ecological Studies, University of Uyo, Nigeria.

\subsection{Preparation of the Extract}

The stems were debarked and sectioned into small pieces which were then ground with the aid of a manual grinder; the ground stem was squeezed to obtain the fresh juice after which it was sieved to obtain the fresh juice extract. To determine the stock concentration of the extract, 3 empty beakers were washed and weighed, $1 \mathrm{~mL}$ of the juice extract was dropped in each beaker, after which they were heated till the juice extract dried off, then the beakers were reweighed, final weight was subtracted from the initial weight for each beaker, average result was taken for the three beakers, thus, and stock concentration was determined to be $30 \mathrm{mg} / \mathrm{ml}$.

\subsection{Experimental Animals}

25 albino Wistar rats weighing between 140 and $180 \mathrm{~g}$ were used for this study. The rats were obtained from the Animal House, Faculty of Basic Medicals Sciences, university of Uyo, Uyo, Akwa Ibom State, Nigeria and maintained under standard laboratory conditions with free access to commercial rat chow and clean drinking water ad libitum. The animals were acclimatized for a period of 2 weeks before the commencement of administration of the drug and plant extract.

\subsection{Determination of Median Lethal Dose $\left(\mathrm{LD}_{50}\right)$ of $C$. afer}

Lorke's method was employed to determine the $\mathrm{LD}_{50}$ of fresh juice extract of the stem of $C$. afer. Mice weighing between 16 and $28 \mathrm{~g}$ were obtained and grouped into various groups, consisting of 3 mice in each group. The different groups were administered doses of the extract ranging from $200 \mathrm{mg}$ to $2000 \mathrm{mg}$ of fresh stem juice extract of $C$. afer per kilogram body weight of the experimental animal. All experimental animals were observed for physical signs of toxicity such as convulsion, writhing, gasping, decrease respiratory rate, and death within $24 \mathrm{~h} . \mathrm{LD}_{50}$ was calculated as geometrical means of the maximum dose producing $0 \%$ mortality (A) and minimum dose producing $100 \%$ mortality (B) or the dose that half of the animals will show sign of toxicity and die [17].

$\mathrm{LD}_{50}=\sqrt{ } \mathrm{AB}$

\subsection{Experimental Design}

The animals were randomly selected into five groups with five animals in each group. Group 1 was the control group while Group 2 was administered $150 \mathrm{mg} / \mathrm{kg}$ body weight of aspirin daily for 28 days, Group 3 received $67.08 \mathrm{mg} / \mathrm{kg}$ body weight of fresh juice extract of the stem of $C$. afer daily for 28 days, Group 4 was administered with $67.08 \mathrm{mg} / \mathrm{kg}$ of fresh juice extract of the stem of C. afer and $150 \mathrm{mg} / \mathrm{kg}$ of aspirin for 28 days, and Group 5 was administered with $150 \mathrm{mg} / \mathrm{kg}$ of aspirin for 14 days, then $67.08 \mathrm{mg} / \mathrm{kg}$ of C. afer for another 14 days. At the end of the experiment, the rats were anesthetized with chloroform, the abdomen was carefully opened, and the kidneys were excised, fixed in $10 \%$ buffered formalin and processed for histological evaluation.

\subsection{Histological Processing of Kidney Tissue}

Organ sections were passed through the processes of fixation, dehydration, clearing, infiltration, embedding, sectioning and staining with Hematoxylin and Eosin, and microscopy as stated by Umoh et al. [18].

\section{RESULTS}

\subsection{Median $\mathrm{LD}_{50}$ of $C$. afer}

The maximum dose of the fresh stem juice extract of $C$. afer producing $0 \%$ mortality was observed to be $200 \mathrm{mg} / \mathrm{kg}$ while the minimum dose producing $100 \%$ mortality was $250 \mathrm{mg} / \mathrm{kg}$. Using Lorke's equation, the $\mathrm{LD}_{50}$ of fresh stem juice extract of $C$. afer was calculated to be $223.61 \mathrm{mg} / \mathrm{kg} .30 \%$ of the $\mathrm{LD}_{50}$ was used for the present study.

\subsection{Histological Results}

Photomicrograph of the kidney of rats in the control group [Plate I] showed normal histological features consisting of the glomerulus, Bowman's capsule, proximal convoluted tubules, distal convoluted tubules, and collecting tubules. Rats in Group 2 which received $150 \mathrm{mg} / \mathrm{kg}$ of aspirin daily for 28 days histologically revealed that the glomeruli and the tubules were severely affected shown in Plate II. Plate III revealed near normal histological features in the kidney of rats which were treated with $67.08 \mathrm{mg} / \mathrm{kg}$ of the stem juice extract of C. afer. However, mild distortion of the glomerulus and tubular lining was also observed compared to the control group. The administration of $150 \mathrm{mg} / \mathrm{kg}$ of the aspiring and $67.08 \mathrm{mg} / \mathrm{kg}$ of the extract for 28 days (Group 4) mildly affected the kidney. Inflamed tubular cells, enlargement of the urinary space, and reduced podocytes were observed [Plate IV]. The kidney of rats from Group 5 showed signs of the regeneration of features already destroyed by administration of aspirin. Regenerated glomerulus and Bowman's capsule [Plate V] were observed compared to Group 2.

\section{DISCUSSION}

The present study is investigated the effect of fresh stem juice extract of $C$. afer on Wistar rats with nephrotoxicity induced by aspirin administration. An undiluted juice extract from the stem of $C$. afer exhibits high toxicity, as reflected in its low $\mathrm{LD}_{50}$. It has been reported

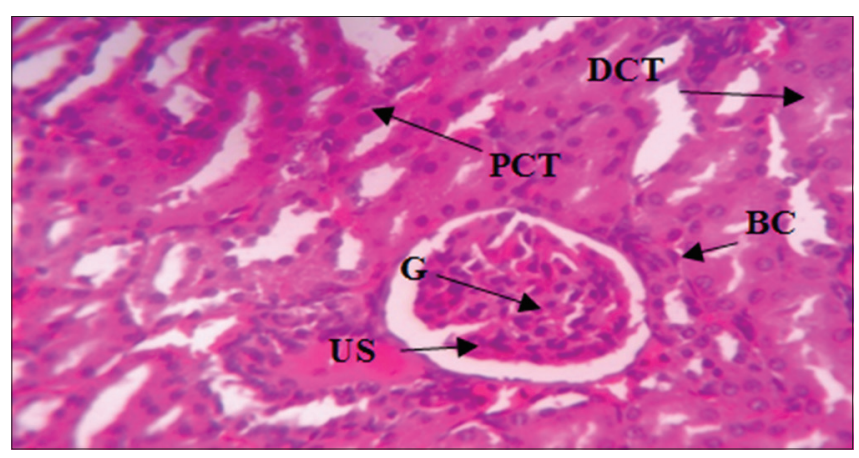

Plate 1: Photomicrograph of the kidney of control group (Group 1) without treatment showing normal urinary space (US), glomerulus (G), Bowman's capsule (BC), proximal convoluted tubule (PCT), distal convoluted tubule (DCT), and Hematoxylin and Eosin stain. Mag. $\times 400$ 


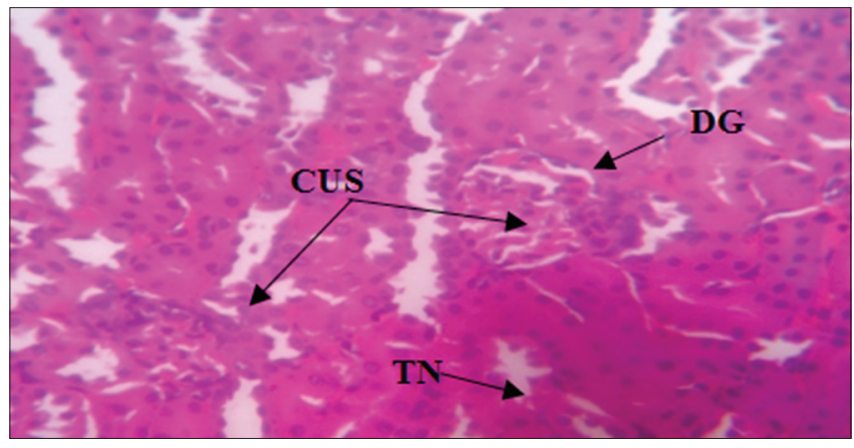

Plate 2 :Photomicrograph of the kidney of Group 2 administered with $150 \mathrm{mg} / \mathrm{kg}$ of Aspirin daily for 28 days showing tubular necrosis, collapsed urinary space, distorted glomerulus, and Hematoxylin and Eosin stain. Mag. $\times 400$

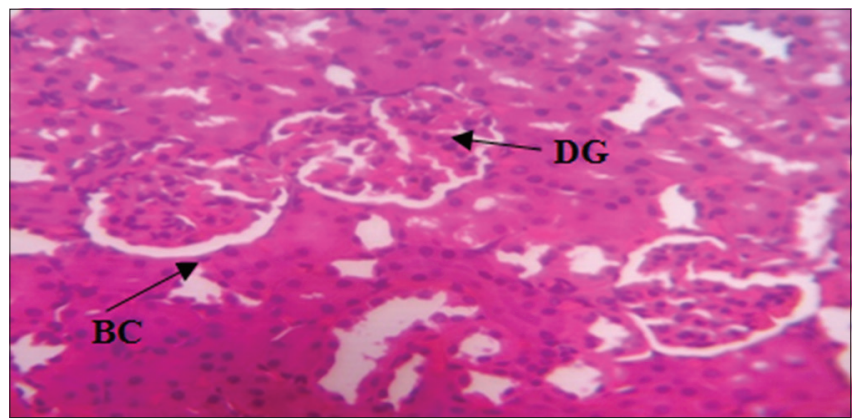

Plate 3: Photomicrograph of the Kidney of Group 3 treated with $67.08 \mathrm{mg} / \mathrm{kg}$ fresh stem extract of Costus afer daily for 28 days showing mildly distorted glomerulus, distinct Bowman's capsule, and Hematoxylin and Eosin stain.

Mag. $\times 400$

that any substance with oral $\mathrm{LD}_{50}$ estimate less than $500 \mathrm{mg}$ of the substance per kilogram body weight of experimental animal can be considered highly toxic and unsafe [19]. Lesion due to lethal effects of some substances is very significant in accessing the health status of the common populace as it serves as an important biomarker of exposure.

Aqueous and ethanol extracts from leaves of $C$. afer have been reported to have neuroprotective effects $[9,20]$. Aspirin suppressed the production of prostaglandins and thromboxanes through irreversible inactivation of the cyclooxygenase (COX) (COX or prostaglandinendoperoxide synthase [PTGS]) enzyme required for PTGS [21]. There are also reports of the adverse effect of this drug on the kidney tissues. [22,23]. Fresh stem juice extract of $C$. afer is frequently consumed for its medicinal potential; however, there is dearth of published scientific information its effect on the kidney. Thus, the histological changes on the kidney of the Wistar rats in this study provide a prerequisite knowledge on the effect of fresh stem juice extract of C. afer on the kidney of aspirin-treated rats.

Nonsteroidal anti-inflammatory drugs such as aspirin exert antiinflammatory, analgesic and antipyretic effects through the suppression of prostaglandin (PG) synthesis by inhibiting the enzyme COX. COX-1 functions mainly in the control of renal hemodynamics and glomerular filtration rate (GFR), while COX-2 function primarily affects salt and water excretion [24]. The suppression of PG and inhibition of COX have the potential to force proteinuria in different types of glomerulonephritis [25-27] and nephrotic syndrome. Thus, blockage of either or both of these enzymes have different effects on renal function of the experimental animals in the present study as shown in aspirin-

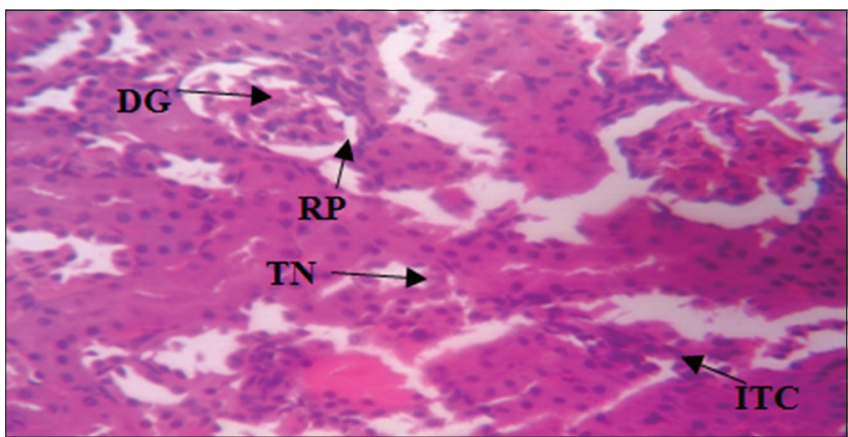

Plate 4: Photomicrograph of the Kidney of Group 4 administered with $150 \mathrm{mg} / \mathrm{kg}$ of Aspirin and $67.08 \mathrm{mg} / \mathrm{kg}$ of fresh stem extract of Costus afer for 28 days showing mild signs of tubular necrosis, reduced podocytes, enlarged urinary space, inflamed tubular cells, distorted glomerulus, and Hematoxylin and Eosin stain. Mag. $\times 400$

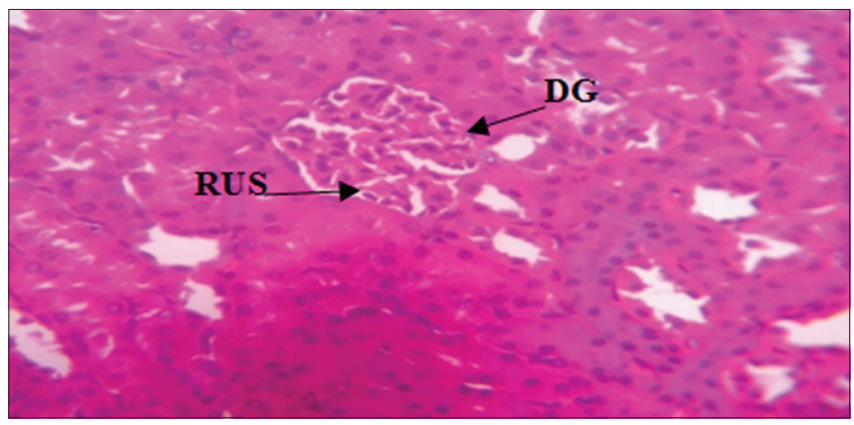

Plate 5: Photomicrograph of the kidney of Group 5 treated with $150 \mathrm{mg} /$ $\mathrm{kg}$ of aspirin for 14 days followed by $67.08 \mathrm{mg} / \mathrm{kg}$ of fresh stem extract of Costus afer for another 14 days showing glomerulus regeneration, reduced urinary space, and Hematoxylin and Eosin stain. Mag. $\times 400$

treated groups when compared to the control, and this is in conformity with a report from other studies [28,29]. The observed changes in the glomerulus and conducting tubules in the experimental groups may be due to immunological mediated lesion causing thickness of glomerular basement membrane and glomerular cell proliferation [30], and this lead to blockage of renal microcirculation. The inflamed glomerulus leads to collapsed urinary space [31]. Tubular necrosis (TN) has also been reported as evidence of aspirin adverse effect on the kidney [23].

Phytochemical analysis of the stem juice extracted from C. afer reveals a high concentration of alkaloids and flavonoids which may be responsible for its anti-inflammatory activities [10]. The histological features in the extract treated group are in alignment with the previous studies on the aqueous and ethanol extracts leaves of $C$. afer which was concluded that it has a protective and anti-inflammatory effect on the kidney $[10-12,16]$. The mild distortion of glomerulus and tubule seen in the extract and aspirin-treated group (Group 4) in the present study may be attributed to the effect of the aspirin which consequently led to a reduction in GFR, reabsorption, and secretion of ions [32]. The photomicrograph of animals in Group 4 implies a protective effect of fresh stem extract of $C$. afer when compared to Group 2. The present study reveals that, in a pathological kidney condition, administration of fresh stem juice extract of $C$. afer seem to ameliorate nephrotoxicity as observed in significant regeneration of aspirin destroyed glomerulus and Bowman's capsule in the photomicrograph of animals in Group 5 treated with aspirin then $C$. afer. 
Renal tubular dilation was also evident in treated groups and may inhibit the reabsorption of sodium ions, secretion of hydrogen and potassium ions thus leading to acute renal failure. Cellular and glomerular inflammation was also depicted. Podocytes in the glomerulus and squamous cells lining the parietal layer of the Bowman's capsule were reduced (Hypoplasia) and degenerated, respectively.

\section{CONCLUSION}

It can be concluded that fresh stem juice extract of $C$. afer at the dosage of $67.08 \mathrm{mg} / \mathrm{kg}$ has ameliorative and protective potentials on the toxic effect of aspirin on the kidney of albino Wistar rats.

\section{REFERENCES}

1. WHO. Traditional Medicine. WHO Document No. WPR/RC52/7; 2015.

2. Acharya D, Shrivastava A. Indigenous Herbal Medicines: Tribal Formulations and Traditional Herbal Practices. Jaipur-India: Aavishkar; 2008. p. 440.

3. Anaga AO, Njoku CJ, Ekejiuba ES, Esiaka MN, Asuzu IU. Investigations of the methanolic leaf extract of costus afer. Ker for pharmacological activities in vitro and in vivo. Phytomedicine 2004;11:242-8.

4. Ukpabi C, Agbafor K, Ndukwe O, Agwu A, Nwachukwu S. Phytochemical composition of Costus afer extract its alleviation of carbon tetrachloride induced hepatic oxidative stress and toxicity. Int J Mod Bot 2012;2:120-6.

5. Edeoga H, Okoli B. Chromosome numbers of Costus lucanusianus (Costaceae) in Nigeria. Folia Geobot 2000;35:315-8.

6. Bukil H. The Useful Plants of West Tropical Africa. Vol. 1. Kew, UK: Royal botanic gardens; 1985. p. 142-6.

7. Aweke G, Schmelzer G, Guribraukin A. Costus afer; Plant Resources of Tropical Africa. Wageningen, Netherlands: Backhuys Publishers; 2007. p. 243.

8. Awouters F, Niemegeers CJ, Lenaerts FM, Janssen PA. Delay of castor oil diarrhoea in rats: A new way to evaluate inhibitors of prostaglandin biosynthesis. J Pharm Pharmacol 1978;30:41-5.

9. Ezejiofor AN, Orish CN, Orisakwe OE. Effect of aqueous leaves extract of Costus afer ker gawl (Zingiberaceae) on the liver and kidney of male albino Wistar rat. Anc Sci Life 2013;33:4-9.

10. Anyasor G, Ogunwenmo K, Olatunji A, Blessing E. Phytochemical constituents and antioxidant activities of aqueous and methanol stem extracts of Costus afer. Afr J Biotechnol 2010;9:4880-2.

11. Sofowora A. Medicinal Plants and Traditional Medicine in Africa. Ibadan: Spectrum Books Ltd.; 2006. p. 150.

12. Okwu D, Okwu M. Chemical composition of Spondias mombim Linn plants parts. J Sustain Agric Environ 2004;6:140-7.

13. Leverin G, McMatron H. Alkaloids and glycosides. Clin Microbiol Rev 1999;11:156-250.

14. Müller-Lissner SA. Adverse effects of laxatives: Fact and fiction. Pharmacology 1993;47 Suppl 1:138-45.

15. Ayoola G, Folawewo A, Adesegun S, Abioro O, Adepoju-Bello A,
Coker H. Phytochemical and antioxidant screening of some plants of Apocynaceae from South West Nigeria. Afr J Plant Sci 2008;2:124-8.

16. Del-Rio A, Obdulio B, Castillo J, Marrin R, Ortuno A. Uses and properties of citrus flavonoids. J Agric Food Chem 1997;4:4505-15.

17. Lorke D. A new approach to practical acute toxicity testing. Arch Toxicol 1983;54:275-87.

18. Umoh IU, Ekanem AU, Bassey UE. Histomorphological effects of quinine and triple antiretroviral regimen (efavirenz/lamivudine/ tenofovir) on fetal kidney of Albino Wistar rats. SSRG Int J Med Sci 2017;4:10-6.

19. UFT. How Toxic is Toxic. Know the Common Measure that Toxicologists Use. Available from: http://www.uft.org. [Last retrieved on 2017 Oct 05].

20. Uboh F, Ufot S, Mbosowo E, Eyong E. Effect of Costus afer leaves' juice on nitrocellulose thinner induced neprotoxicity in rats. Res J Environ Toxicol 2014;8:37-45.

21. Vane JR, Botting RM. The mechanism of action of aspirin. Thromb Res 2003;110:255-8.

22. Cotran R, Kumar V, Fausto N, Robbins S, Abbas A. Pathologic Basis of Disease. Philadelphia, PA: Elsevier Saunders; 2005. p. 216-8.

23. Macdonald S. Aspirin use to be banned in under 16 year olds. BMJ 2002;325:988.

24. Weir MR. Renal effects of nonselective NSAIDs and coxibs. Cleve Clin J Med 2002;69 Suppl 1:SI53-8.

25. Perico N, Remuzzi A, Sangalli F, Azzollini N, Mister M, Ruggenenti P, et al. The antiproteinuric effect of angiotensin antagonism in human IgA nephropathy is potentiated by indomethacin. J Am Soc Nephrol 1998;9:2308-17.

26. Zola C, Benigni A, Verroust P, Ronco P, Bertani T, Remuzzi G. Indomethacin reduces proteinuria in passive heymann nephritis in rats. Nephritis. J Pharmacol Exp Ther 1998;31:1335-43.

27. Takano T, Cybulsky AV, Cupples WA, Ajikobi DO, Papillon J, Aoudjit L, et al. Inhibition of cyclooxygenases reduces complementinduced glomerular epithelial cell injury and proteinuria in passive heymann nephritis. J Pharmacol Exp Ther 2003;305:240-9.

28. Nantel F, Meadows E, Denis D, Connolly B, Matters K, Giaid A. Immunolocalization of cyclooxynase-2 in the meculadensa of human elderly. J Am Soc Nephrol 1999;457:475-7.

29. Schnermann J, Briggs J. The macula densa is worth its salt. J Clin Invest 1999;104:1007-9.

30. Calado A. Experimental pathology and health sciences. Am Soc Health Syst Pharm 2013;7:168-76.

31. Patrick H, Nachman J, Ronald J. Primary Glomerular Disease: Saunders Imprint of Elsevier; 2012. p. 215.

32. Eroschenko V. Di Fiore's Atlas of Histology with Functional Correlations. $11^{\text {th }}$ ed. Philadelphia, PA: Lippincott Williams and Wilkins; 2008. p. 394-405.

\footnotetext{
How to cite this article:

Umoh IU, Aquaisua AN, Udo NM. The effect of fresh stem juice extract of

Costus afer on the cytohistomorphology of the kidney in aspirin-treated Wistar rats. J App Biol Biotech. 2019;7(02):78-81. DOI: 10.7324/JABB.2019.70214
} 